\title{
Development of the Global Sea Ice 6.0 CICE configuration for the Met Office Global Coupled model
}

\author{
J. G. L. Rae ${ }^{1}$, H. T. Hewitt ${ }^{1}$, A. B. Keen ${ }^{1}$, J. K. Ridley ${ }^{1}$, A. E. West ${ }^{1}$, C. M. Harris ${ }^{1}$, E. C. Hunke ${ }^{2}$, and D. N. Walters ${ }^{1}$ \\ ${ }^{1}$ Met Office Hadley Centre, FitzRoy Road, Exeter, EX1 3PB, UK \\ ${ }^{2}$ MS-B216, Los Alamos National Laboratory, Los Alamos, NM 87545, USA \\ Correspondence to: J. G. L. Rae (jamie.rae@metoffice.gov.uk)
}

Received: 10 February 2015 - Published in Geosci. Model Dev. Discuss.: 5 March 2015

Revised: 30 June 2015 - Accepted: 3 July 2015 - Published: 24 July 2015

\begin{abstract}
The new sea ice configuration GSI6.0, used in the Met Office global coupled configuration GC2.0, is described and the sea ice extent, thickness and volume are compared with the previous configuration and with observationally based data sets. In the Arctic, the sea ice is thicker in all seasons than in the previous configuration, and there is now better agreement of the modelled concentration and extent with the HadISST data set. In the Antarctic, a warm bias in the ocean model has been exacerbated at the higher resolution of GC2.0, leading to a large reduction in ice extent and volume; further work is required to rectify this in future configurations.
\end{abstract}

\section{Introduction}

Within the Met Office's model development framework, there are four model components: atmosphere, using the Met Office Unified Model (MetUM, see Cullen and Davies, 1991; Davies et al., 2005); land surface, using the Joint UK Land Environment Simulator (JULES, see Best et al., 2011); ocean, using the Nucleus for European Modelling of the Ocean (NEMO, see Madec, 2008); and sea ice, using the Los Alamos Sea Ice Model, CICE (Hunke and Lipscomb, 2010). The UM and JULES run together as one executable, as do NEMO and CICE. UM-JULES and NEMO-CICE communicate via the OASIS coupler (Valcke, 2006).

The Met Office configurations of each component are known as Global Atmosphere (GA), Global Land (GL), Global Ocean (GO) and Global Sea Ice (GSI), and the combined system is known as the Global Coupled (GC) configuration. These terms are suffixed by a version number (e.g. "GA6.0", "GC2.0"). The second coupled configuration, GC2.0 (Williams et al., 2015), includes GA6.0 and GL6.0 (both described by Walters et al., 2015), GO5.0 (Megann et al., 2014) and GSI6.0. GC2.0 will be used on a range of spatial scales (regional and global), and on a range of temporal scales, from ocean forecasting (FOAM; see Blockley et al., 2014), through seasonal and decadal prediction (GloSea5; see MacLachlan et al., 2014), to centennial-scale climate projections (HadGEM3; see Hewitt et al., 2011). In the present paper, we consider only the climate configuration, HadGEM3.

Sea ice is a key component of the Earth system because of its role in the energy balance of the polar regions. An accurate simulation of sea ice is therefore essential in fully coupled atmosphere-ocean-ice models run on any timescale. Here, we describe the model set-up and parametrisations used in GSI6.0 as part of GC2.0, and discuss how the change from the previous configuration (GSI4.0) to GSI6.0 has affected simulated sea ice extent, thickness and volume.

\section{Description of GSI6.0}

Thorndike et al. (1975) defined the ice thickness distribution (ITD), $g$, as a probability density function such that $g(h) \mathrm{d} h$ is the fraction of ice in thickness range $h$ to $h+\mathrm{d} h$. The evolution of $g(h)$ with time is described by the governing equation:

$\frac{\partial g}{\partial t}=-\nabla \cdot(\boldsymbol{v} g)-\frac{\partial(\Phi g)}{\partial h}+\psi$,

where $\nabla \cdot(\boldsymbol{v g})$ is the rate of change of $g$ due to dynamical processes ( $v$ is the ice velocity), $\Phi$ is the rate of change of 
ice thickness due to thermodynamic growth and melt, and $\psi$ gives the contribution from mechanical redistribution (ridging). A full explanation is given by Thorndike et al. (1975). The CICE sea ice model solves this equation to determine the evolution of $g$ in time and space. Full details of the model are available in the CICE user manual (Hunke and Lipscomb, 2010); here we summarise the main features of the model used in GSI, and detail the specific settings and choices for the previous configuration (GSI4.0) and the new configuration (GSI6.0). Much of the basic model description is provided in Appendix D of Hewitt et al. (2011), but it is reproduced here for completeness.

\subsection{Horizontal and vertical discretisation}

The GSI configurations discussed here use code revision 430 of CICE version 4.1, which allows a tripolar grid to be employed. These configurations use essentially the same family of ORCA grids as the NEMO model (see Appendix C of Hewitt et al., 2011), although CICE uses an Arakawa B grid rather than a $\mathrm{C}$ grid and so the CICE velocity grid points are not coincident with the NEMO velocity points. The grid and land-mask definitions required by CICE are read in directly from a file, as are the initial conditions. The sub-grid-scale ITD is modelled by dividing the ice pack at each grid point into a number of thickness categories. GSI uses five categories, plus an open-water category, which has been shown to be sufficient for climate modelling (Bitz et al., 2001). The lower bounds for the five thickness categories are 0, 0.6, 1.4, 2.4 and $3.6 \mathrm{~m}$. GSI uses the zero-layer thermodynamic model of Semtner (1976) to calculate the growth and melt of the sea ice, with one layer of snow and one layer of ice in the vertical. This is not the standard scheme implemented in CICE, which has a multilayer ice model (Bitz and Lipscomb, 1999). It was not possible to use the CICE multilayer thermodynamics in GSI because the surface temperature at sea ice points, and the conductive heat flux into the ice, is currently calculated by the JULES land-surface model (which also models surface exchange over the ocean and sea ice). This would not be consistent with the CICE multilayer thermodynamics scheme, which calculates these quantities itself, so for GSI CICE has been adapted to use the zero-layer surface fluxes received from the UM atmosphere.

\subsection{Thermodynamics}

As discussed in the previous section, the GSI configurations use five ice thickness categories in the CICE model. While the conductive heat fluxes through the ice are calculated in the JULES land-surface model on these five categories, the ice albedo and the turbulent (latent and sensible) heat fluxes are currently calculated as grid-box means.

The sea ice albedo is calculated as a function of temperature and snow cover, including a parametrisation to represent the impact of melt ponds, and - in the zero-layer model
- a parametrisation to account for the effects of scattering. This is the same scheme used in HadGEM1 (McLaren et al., 2006), HadGEM2 (HadGEM2 Development Team, 2011) and HadGEM3 (Hewitt et al., 2011). The total albedo is calculated from the ice albedo $\alpha_{\mathrm{i}}$ and the snow albedo $\alpha_{\mathrm{s}}$, following the parametrisation of Essery et al. (1999),

$\alpha_{\text {tot }}=\alpha_{\mathrm{i}}+\left(\alpha_{\mathrm{i}}-\alpha_{\mathrm{s}}\right)(1-\exp (-0.2 S))$,

where $S$ is the mass of snow per unit area.

Bare ice albedo $\alpha_{\mathrm{b}}$ is set as a single value. The ice albedo $\alpha_{\mathrm{i}}$ is then calculated by applying corrections to $\alpha_{\mathrm{b}}$ to account for the presence of melt ponds, and for scattering within the ice pack. Melt ponds are assumed to form on bare ice when the ice temperature reaches a threshold temperature $T_{\mathrm{p}}$. As the temperature increases between $T_{\mathrm{p}}$ and the melting temperature $T_{\mathrm{m}}$, melt ponds are assumed to reduce the ice albedo $\alpha_{\mathrm{i}}$ linearly,

$\alpha_{\mathrm{i}}=\left\{\begin{array}{ll}\alpha_{\mathrm{b}} & \text { if } T<T_{\mathrm{p}} \\ \alpha_{\mathrm{b}}+\frac{\mathrm{d} \alpha_{\mathrm{i}}}{\mathrm{d} T}\left(T-T_{\mathrm{p}}\right) & \text { if } T_{\mathrm{p}} \leq T \leq T_{\mathrm{m}}\end{array}\right.$,

where $T_{\mathrm{m}}$ is fixed at $0^{\circ} \mathrm{C}$ for all simulations, while the values of $T_{\mathrm{p}}$ and $\frac{\mathrm{d} \alpha_{\mathrm{i}}}{\mathrm{d} T}$ can be set as parameters for each simulation.

Because the ice model configuration uses a zero-layer approximation, an additional parametrisation is required to account for the effects of internal scattering (e.g. from brine pockets) on the albedo. Following the suggestion of Semtner (1976), a correction $\Delta \alpha_{\mathrm{i}}$ is applied to the ice albedo,

$\Delta \alpha_{\mathrm{i}}=f \beta\left(1-\alpha_{\mathrm{i}}\right)$,

where $f$ is the fraction of incident radiation that penetrates the ice pack, and $\beta$ is an attenuation factor to take account of backscatter.

Snow albedo $\alpha_{\mathrm{s}}$ is assumed to vary linearly with temperature between that of cold, dry snow $\left(\alpha_{\mathrm{c}}\right)$ at a threshold temperature $T_{\mathrm{c}}$, and that of melting snow $\left(\alpha_{\mathrm{m}}\right)$ at the melting point, $T_{\mathrm{m}}$,

$\alpha_{\mathrm{s}}=\left\{\begin{array}{ll}\alpha_{\mathrm{c}} & \text { if } T<T_{\mathrm{c}} \\ \alpha_{\mathrm{c}}+\frac{\alpha_{\mathrm{m}}-\alpha_{\mathrm{c}}}{T_{\mathrm{m}}-T_{\mathrm{c}}}\left(T-T_{\mathrm{c}}\right) & \text { if } T_{\mathrm{c}} \leq T \leq T_{\mathrm{m}}\end{array}\right.$,

where $T_{\mathrm{m}}$ is fixed at $0{ }^{\circ} \mathrm{C}$, while $T_{\mathrm{c}}, \alpha_{\mathrm{c}}$ and $\alpha_{\mathrm{m}}$ can be varied.

As in HadGEM1, the sea ice surface temperature and the atmosphere-to-ice fluxes are calculated in JULES (see McLaren et al., 2006, for details). Within CICE these fluxes (downward latent heat flux, surface sensible heat flux, and conductive flux through the ice), along with the ocean-ice heat flux (McPhee, 1992), determine the rate at which the ice grows or melts in each thickness category. The calculated thermodynamic growth or melt rates are then used in the linear remapping scheme of Lipscomb (2001) to exchange the ice between thickness categories.

\subsection{Dynamics and ridging}

The ice velocities are calculated by solving the 2-D momentum equation for the force balance per unit area in the ice 
Table 1. Model set-up and values of sea ice parameters in GSI4.0 and GSI6.0 simulations.

\begin{tabular}{|c|c|c|c|}
\hline & & GSI4.0 & GSI6.0 \\
\hline CICE revision number & & 430 & 430 \\
\hline Atmosphere configuration (UM version) & & GA4.0 (UM8.2) & GA5.0 (UM8.5) \\
\hline Land surface configuration (UM version) & & GL4.0 (UM8.2) & GL5.0 (UM8.5) \\
\hline Ocean configuration (NEMO version) & & GO4.0 (NEMO 3.4) & GO5.0 (NEMO 3.4) \\
\hline Coupled configuration & & N/A & $\mathrm{GC} 2.0$ \\
\hline Atmosphere model resolution & & N96 & N96 \\
\hline Ocean-ice model resolution & & ORCA1 & ORCA025 \\
\hline \multirow{8}{*}{$\begin{array}{l}\text { Parameters affecting albedo } \\
\text { and radiative forcing } \\
\text { (see Sect. 2.2) }\end{array}$} & $\alpha_{\mathrm{b}}$ & 0.61 & 0.61 \\
\hline & $\alpha_{\mathrm{c}}$ & 0.80 & 0.80 \\
\hline & $\alpha_{\mathrm{m}}$ & 0.65 & 0.72 \\
\hline & $T_{\mathrm{c}}$ & $-2.0^{\circ} \mathrm{C}$ & $-2.0^{\circ} \mathrm{C}$ \\
\hline & $T_{\mathrm{p}}$ & $-1.0^{\circ}$ & $-1.0^{\circ}$ \\
\hline & $\mathrm{d} \alpha_{\mathrm{i}} / \mathrm{d} T$ & $-0.075^{\circ} \mathrm{C}^{-1}$ & $-0.075^{\circ} \mathrm{C}^{-1}$ \\
\hline & $f$ & 0.17 & 0.20 \\
\hline & $\beta$ & 0.4 & 0.6 \\
\hline \multirow{2}{*}{$\begin{array}{l}\text { Roughness lengths } \\
\text { (see Sect. } 2.8 \text { of Rae et al., 2014) }\end{array}$} & $z_{0}(\mathrm{MIZ})$ & $0.0005 \mathrm{~m}$ & $0.100 \mathrm{~m}$ \\
\hline & $z_{0}($ ice $)$ & $0.0005 \mathrm{~m}$ & $0.003 \mathrm{~m}$ \\
\hline \multicolumn{4}{|l|}{ (see Sect. 2.7 of Rae et al., 2014) } \\
\hline $\begin{array}{l}\text { Ridging parameter } \\
\text { (see Sect. } 2.6 \text { of Rae et al., 2014) }\end{array}$ & $\mu_{\text {rdg }}$ & $4.0 \mathrm{~m}^{1 / 2}$ & $3.0 \mathrm{~m}^{1 / 2}$ \\
\hline \multirow{2}{*}{$\begin{array}{l}\text { Thermal conductivities } \\
\text { (see Sect. } 2.4 \text { of Rae et al., 2014) }\end{array}$} & $\kappa_{\text {ice }}$ & $2.09 \mathrm{~W} \mathrm{~m}^{-1} \mathrm{~K}^{-1}$ & $2.63 \mathrm{~W} \mathrm{~m}^{-1} \mathrm{~K}^{-1}$ \\
\hline & $\kappa_{\text {snow }}$ & $0.31 \mathrm{~W} \mathrm{~m}^{-1} \mathrm{~K}^{-1}$ & $0.50 \mathrm{~W} \mathrm{~m}^{-1} \mathrm{~K}^{-1}$ \\
\hline
\end{tabular}

pack (Hibler, 1979), including terms for wind stress, ocean stress, internal ice stress, and stresses due to Coriolis effects. The internal ice stress is calculated using the elastic viscous plastic (EVP) scheme (Hunke and Dukowicz, 2002), which assumes the ice has a viscous plastic rheology, and incorporates an elastic wave modification to improve the computational efficiency. The GSI configurations use the Rothrock et al. (1975) formulation for ice strength. The sea ice is advected using the CICE incremental remapping scheme (Lipscomb and Hunke, 2004). The mechanical redistribution (or ridging) scheme in CICE converts thinner ice to thicker ice and open water, and is applied after the advection of ice. The scheme is based on work by Thorndike et al. (1975), Hibler (1980), Flato and Hibler (1995), and Rothrock et al. (1975). It favours the closing of open water and ridging of the thinnest ice over the ridging of thicker ice. In GSI the ridging participation function suggested by Lipscomb et al. (2007) is used. The ridged ice is then distributed between thickness categories assuming an exponential ITD (Lipscomb et al., 2007).

\subsection{CICE settings used for GSI6.0}

Rae et al. (2014) investigated the sensitivity of Arctic and Antarctic sea ice extent, thickness and volume in GSI4.0 to changes in several sea ice physical parameters, as well as to changes in the resolutions of the atmosphere and ocean models. By testing each of these sensitivities in isolation, they identified an optimum set of sea ice parameters for use in the Met Office coupled configuration. They found the Arctic sea ice to be most sensitive to changes in the albedos and thermal conductivities of ice and snow, while the Antarctic sea ice was most sensitive to changes in ice salinity, atmospheric and oceanic forcing, and ice-ocean model resolution.

This forms the basis for the set of parameters used in GSI6.0, with some adjustments to account for the effect of changes in the atmosphere model made at the same time (see Walters et al., 2015). Parameter values are given in Table 1. The CICE namelist used in GSI6.0, which has been edited to detail the scientific options only, is given in Appendix A. The albedo parameters $\alpha_{\mathrm{m}}, f$ and $\beta$ were set in such a way as to increase the surface albedo, thereby reducing summer melt; the other albedo parameters were left unchanged. The values of the thermal conductivities of ice and snow, $\kappa_{\text {ice }}$ and $\kappa_{\text {snow }}$, were chosen to increase the heat flux through the ice in autumn and winter, thereby increasing ice growth. The ice salinity, $S$, was increased, because Rae et al. (2014) found that this led to greater Antarctic ice growth due to a colder ocean mixed layer through the effect of salinity on ocean mixing. Rae et al. (2014) found the Arctic and Antarctic sea 
Table 2. The preprocessor keys used for CICE in GC2.0-GSI6.0.

\begin{tabular}{|c|c|}
\hline Preprocessor key & Purpose \\
\hline coupled & Coupled run \\
\hline ncdf & NetCDF format options available for input and output files \\
\hline CICE_IN_NEMO & $\begin{array}{l}\text { CICE is run in the NEMO environment. CICE is called from the NEMO } \\
\text { surface module, which also exchanges the coupling fields between NEMO and CICE }\end{array}$ \\
\hline ORCA_GRID & Controls reading in grid, land masks and forcing data on the ORCA family of grids. \\
\hline key_oasis3 & Coupling uses OASIS3 \\
\hline REPRODUCIBLE & Ensures global sums bit compare for parallel model runs with different grid decompositions \\
\hline
\end{tabular}

ice extent and volume to be relatively insensitive to the value of the ridging parameter $\mu_{\text {rdg }}$ (Hunke, 2010); however, the value was reduced from 4 to $3 \mathrm{~m}^{1 / 2}$ as this is now the recommended value. The roughness lengths of pack ice and the marginal ice zone, $z_{0}$ (ice) and $z_{0}$ (MIZ), previously had different values in the climate and numerical weather prediction (NWP) configurations of the model. In GSI6.0, the values in the climate configuration have been increased to make them consistent with those in the NWP configuration.

For coupling with the UM atmosphere, heat_capacity and calc_Tsfc are both set to false. This means that zero-layer thermodynamics are used and that CICE does not calculate any surface fluxes or the surface ice temperature. Note that setting calc_tsfc to false also means that the albedo settings in the CICE namelist are irrelevant as the albedo is not calculated by CICE. Wind stresses are passed from the UM atmosphere rather than being calculated in CICE, so calc_strair is set to false. A constant value for the freezing point of seawater is used $\left(-1.8^{\circ} \mathrm{C}\right)$, by setting Tfrzpt $=$ ' constant'. This is required for consistency with the UM atmosphere-ice thermodynamics. The variable ns_boundary_type is set to tripole for the ORCA1 grid (i.e. in GSI4.0), indicating a tripolar grid with the "north fold" occurring along velocity points. The alternative setting tripoleT is used for the ORCA025 grid (i.e. in GSI6.0) where the north fold occurs along temperature points. The CICE preprocessor keys used in HadGEM3 at GC2.0 are shown in Table 2.

\section{Experimental set-up}

We compare sea ice simulations from GSI6.0 (within GC2.0) with those from the previous configuration, GSI4.0 (within an earlier configuration of the coupled model). Both simulations were performed with a fully coupled configuration of the Met Office's modelling system. The atmosphere and land-surface models were run on an N96 grid (equivalent to a resolution of $1.875^{\circ}$ in longitude and $1.25^{\circ}$ in latitude); the ocean and sea ice models were on an ORCA1 grid (nominal $1^{\circ}$ resolution) for GSI4.0, and an ORCA025 grid (nominal $0.25^{\circ}$ resolution) for GSI6.0. The model set-ups and pa- rameter values used are given in Table 1. Both simulations used initial conditions, greenhouse gas concentrations, and emissions of aerosols and their precursors appropriate for the present day (equivalent to year 2000). In both cases, we consider 50 years of output following an 80-year spin-up.

\section{Model evaluation}

In GSI4.0, the Arctic ice volume (Fig. 2c; Table 3) was too low relative to that from the Pan-Arctic Ice-Ocean Modeling and Assimilation System (PIOMAS, see Schweiger et al., 2011), a coupled ice-ocean model that includes assimilation of observations. The findings of Rae et al. (2014), and the poor agreement of GSI4.0 Arctic sea ice with observational data sets, informed the choice of parameter values for GSI6.0 (see Table 1). In this section, the differences between GSI6.0 and GSI4.0 will be discussed, and put in the context of the findings of Rae et al. (2014). That study found that snow albedo, and snow and ice thermal conductivities, had the largest effect on Arctic sea ice, and that the winter Arctic ice extent was strongly influenced by a move to higher ice-ocean model resolution, through its effect on seasurface temperatures in the Labrador Sea. Rae et al. (2014) also found that in the Antarctic, the effects of changing atmospheric and oceanic forcing generally dominated over those of changing sea ice parameters, and that the Antarctic sea ice simulation in the model was also strongly sensitive to increased ice-ocean resolution.

\subsection{Arctic}

In GSI6.0, we see thickening of the Arctic ice pack at the end of winter relative to GSI4.0 (Fig. 1a, b), resulting in improved agreement with observations (see Fig. 1 of Laxon et al., 2013). The net melting or growth of Arctic sea ice is the residual of the energy balance, and is extremely sensitive to small changes in the fluxes at the top and bottom of the ice pack (Keen et al., 2013). Rae et al. (2014) found that increased ice and snow thermal conductivities cause an increased upward conductive heat flux through the ice pack in late summer and early autumn, leading to subtle shifts in the energy budget within the ice pack. This results in reduced 
Table 3. 50-year mean sea ice extent and volume in GSI4.0 and GSI6.0, and equivalent 11-year (1995-2004) means for HadISST and PIOMAS data.

\begin{tabular}{lllrrrr}
\hline Quantity & & & GSI4.0 & GSI6.0 & HadISST & PIOMAS \\
\hline Sea ice extent $\left(10^{6} \mathrm{~km}^{2}\right)$ & \multirow{2}{*}{ Arctic } & Mar & 17.68 & 14.70 & 15.81 & - \\
& & Sep & 3.88 & 7.58 & 7.23 & - \\
& \multirow{2}{*}{ Antarctic } & Sep & 19.59 & 12.67 & 20.24 & - \\
& & Mar & 1.43 & 0.46 & 5.74 & - \\
\hline \multirow{2}{*}{ Sea ice volume $\left(10^{3} \mathrm{~km}^{3}\right)$} & \multirow{2}{*}{ Arctic } & Mar & 20.95 & 27.50 & - & 26.89 \\
& & Sep & 1.96 & 10.81 & - & 11.56 \\
& \multirow{2}{*}{ Antarctic } & Sep & 12.12 & 6.46 & - & - \\
& & Mar & 0.73 & 0.11 & - & - \\
\hline
\end{tabular}

(a) GSI4.0 Mar thickness

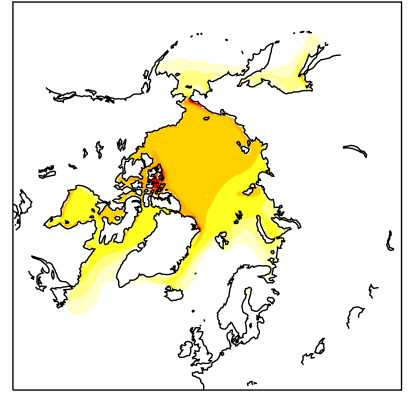

(c) GSI4.0 Sept thickness

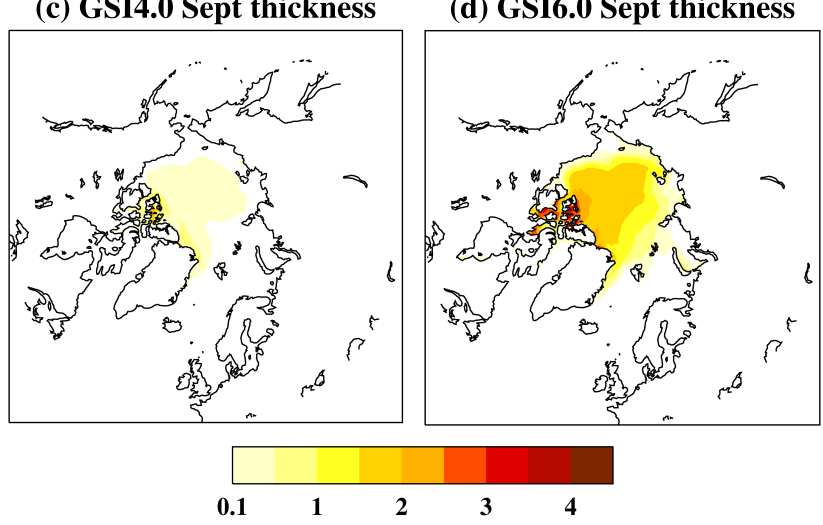

Figure 1. March and September 50-year mean Arctic sea ice thickness (m) in GSI4.0 and GSI6.0.

basal melt in July and August, and increased basal growth in winter, leading to increased thickness, extent and volume.

We also see an increase in summer ice extent, thickness and volume in GSI6.0 compared to GSI4.0 (Figs. 1c, d, 3d, e, 2a, 2c; Table 3). This mirrors the behaviour seen by Rae et al. (2014) with increased ice and snow thermal conductivities, where the increased ice thickness seen in winter persisted through the following melt season. In addition to this, Rae et al. (2014) also found that in the Arctic increased snow albedo led to reduced surface melt in summer, and thus to increased summer ice extent, thickness and volume. It is likely that similar effects are occurring here in GSI6.0. The sum- mer ice concentration and extent are now more in agreement with the HadISST data set of Rayner et al. (2003) (Figs. 3f, $2 \mathrm{a})$, and the agreement of the volume with PIOMAS has also improved (Fig. 2c; Table 3).

In winter, there are also overall improvements in the total extent relative to HadISST (Fig. 2a; Table 3), largely due to reduced ice cover in the Labrador Sea (Fig. 3a, b, c). The investigations of Rae et al. (2014) suggest that this is attributable to the increased ice-ocean model resolution. They found that the increased resolution led to warmer sea-surface temperatures in the Labrador Sea, leading in turn to a reduced sea ice concentration there, and thus to a lower total Arctic winter sea ice extent. Despite this reduced winter ice extent, the increased ice thickness has led to an increased ice volume, with the result that it is now more in agreement with that from PIOMAS (Fig. 2c; Table 3).

\subsection{Antarctic}

The GC simulations have been found to display a warm bias in sea-surface temperatures (SST) in the Southern Ocean (Megann et al., 2014), due to a positive bias in downward heat flux from the atmosphere into the ocean (Williams et al., 2015). In GSI4.0, this led to a low Antarctic sea ice extent in austral summer, although the winter ice extent compared favourably with HadISST (Fig. 2b; Table 3).

Rae et al. (2014) found that the Antarctic ice extent and volume were generally insensitive to perturbations in the ice physics parameters (other than salinity), but that the effects of the warm SST bias were exacerbated at higher ice-ocean resolution. They attributed this to the removal of the GentMcWilliams eddy parametrisation at the eddy-permitting resolution of ORCA025. It is thought that this parametrisation helps to mask the warm bias at lower resolution, but that its removal in the higher-resolution runs leads to increased southward heat transport in the ocean.

As discussed in Sect. 3, GSI6.0 is run at the higher resolution of ORCA025 (see Table 1). The exacerbation of the warm bias in the Southern Ocean therefore has an impact on the Antarctic sea ice in GSI6.0, and there is a substantial re- 

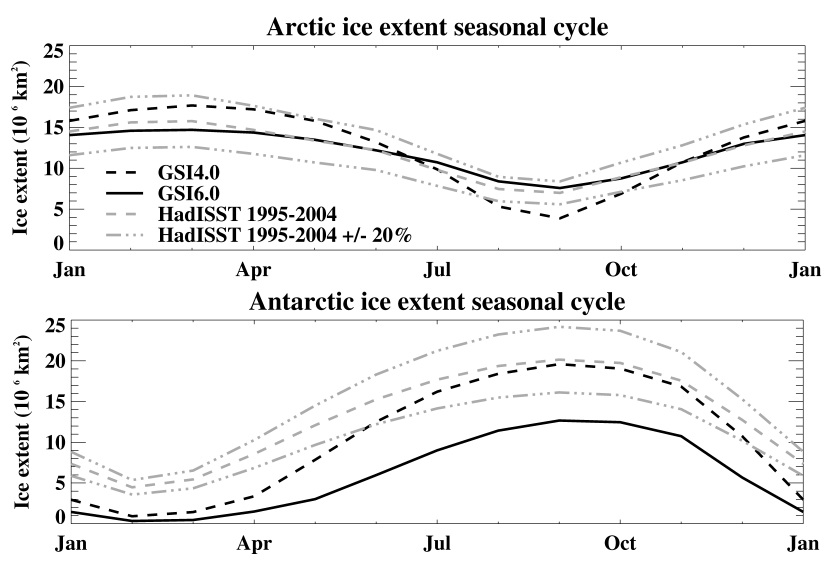

(c) Arctic ice volume seasonal cycle

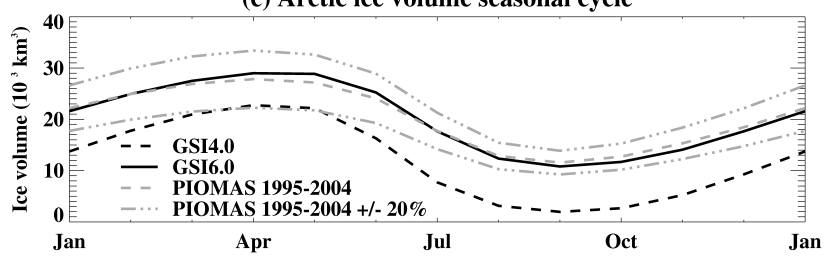

(d) Antarctic ice volume seasonal cycle

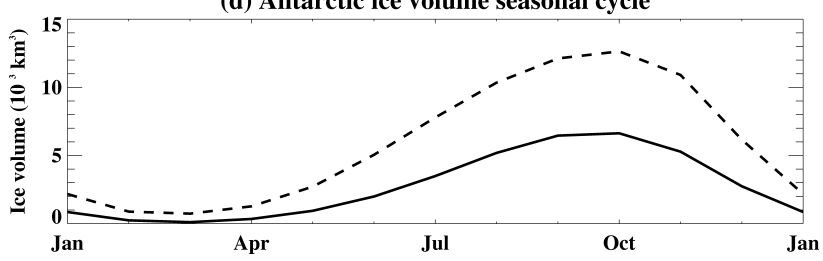

Figure 2. 50-year mean seasonal cycles of sea ice extent and volume in GSI4.0 and GSI6.0, and equivalent 11-year (1995-2004) mean seasonal cycles for the HadISST and PIOMAS data sets.

duction in ice extent and volume in all seasons (Fig. 2b, d; Table 3). Thus, while the transition from GSI4.0 to GSI6.0 leads to some improvements in the Arctic, the same is not true in the Antarctic. Work is ongoing to reduce the warm bias in the Southern Ocean, and it is anticipated that this will lead to improved simulations of Antarctic sea ice in future configurations.

\section{Conclusions}

We have described and evaluated the new Global Sea Ice configuration, GSI6.0, run within the Met Office Global Coupled model configuration GC2.0. The choice of parameters for GSI6.0 was informed by the work of Rae et al. (2014), who conducted an extensive sea ice parameter sensitivity study within the Met Office coupled modelling system and in addition isolated the impact of ice physics changes from that of forcing and resolution changes. In the new configurations, the values of several sea ice parameters have been changed, and the ice-ocean model resolution has been increased from ORCA1 (nominal $1^{\circ}$ resolution) to ORCA025 (nominal $0.25^{\circ}$ resolution). This has resulted in thicker Arc- (a) GSI4.0 March concentration

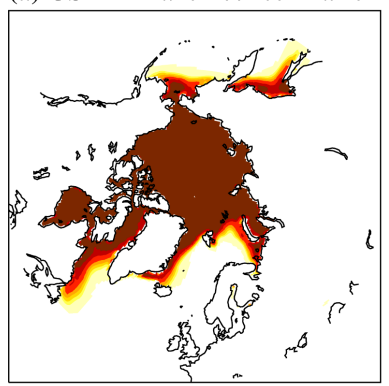

(c) HadISST March concentration

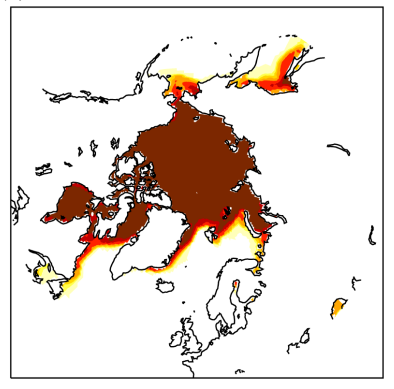

(e) GSI6.0 Sept concentration

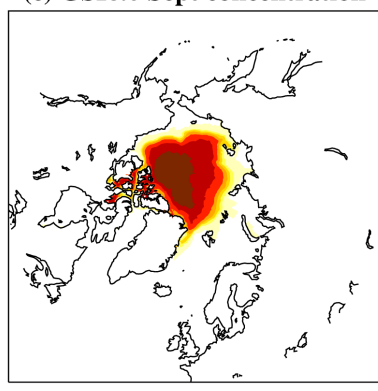

(b) GSI6.0 March concentration

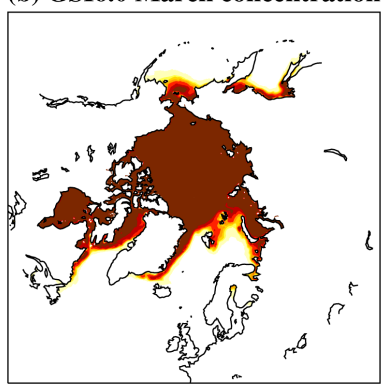

(d) GSI4.0 Sept concentration

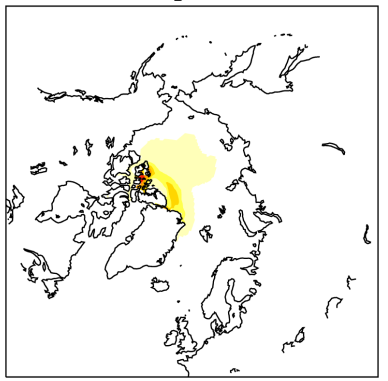

(f) HadISST Sept concentration

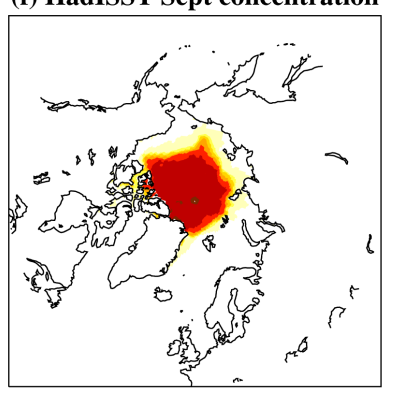

$\begin{array}{lllllll}0.15 & 0.5 & 0.6 & 0.7 & 0.8 & 0.9 & 0.95\end{array}$

Figure 3. March and September 50-year mean Arctic sea ice concentration in GSI4.0 and GSI6.0, and equivalent 11-year (19952004) means for the HadISST data set.

tic ice in all seasons, and Arctic ice concentration and extent that are in better agreement with the HadISST observational data set (Rayner et al., 2003). In the Antarctic, the higher ice-ocean model resolution has resulted in the exacerbation of an existing warm bias in the Southern Ocean. This has in turn led to a large reduction in ice extent and volume. Rectification of this bias will require further development work on atmosphere-ocean heat transfer in the coupled model.

While the sea ice simulation in GSI6.0 represents an improvement over that in GSI4.0 - at least in the Arctic - there are still several areas in which there is potential for further model enhancement. First, while the GSI configurations use five ice thickness categories in the CICE model, and the conductive heat fluxes through the ice are calculated on these categories, as mentioned in Sect. 2.2, the albedo and the surface 
latent and sensible heat fluxes are calculated in the JULES land-surface scheme as gridbox means. In the next configuration, these calculations will be performed on all five thickness categories. Second, the sea ice surface albedo scheme used in GSI4.0 and GSI6.0 is the same broadband scheme used in HadGEM1 (McLaren et al., 2006). The next configuration will include separate calculations for four radiation bands - direct and diffuse radiation for both visible and nearinfrared bands - as well as for each ice thickness category. It is anticipated that future configurations will also include an explicit representation of the effect of melt ponds on sur- face albedo. As mentioned in Sect. 2.4, GSI currently uses a fixed reference value of $-1.8^{\circ} \mathrm{C}$ for the freezing temperature of seawater. In future configurations, this freezing temperature will be calculated as a function of ocean salinity. Finally, as mentioned in Sect. 2.1, the current GSI configurations use the zero-layer thermodynamics of Semtner (1976, 1987), rather than the full multi-layer CICE scheme. Planned modifications to CICE, the UM, and JULES will enable the CICE multilayer model to be used with the UM atmosphere in the future. 


\section{Appendix A: CICE namelist used in GSI6.0}

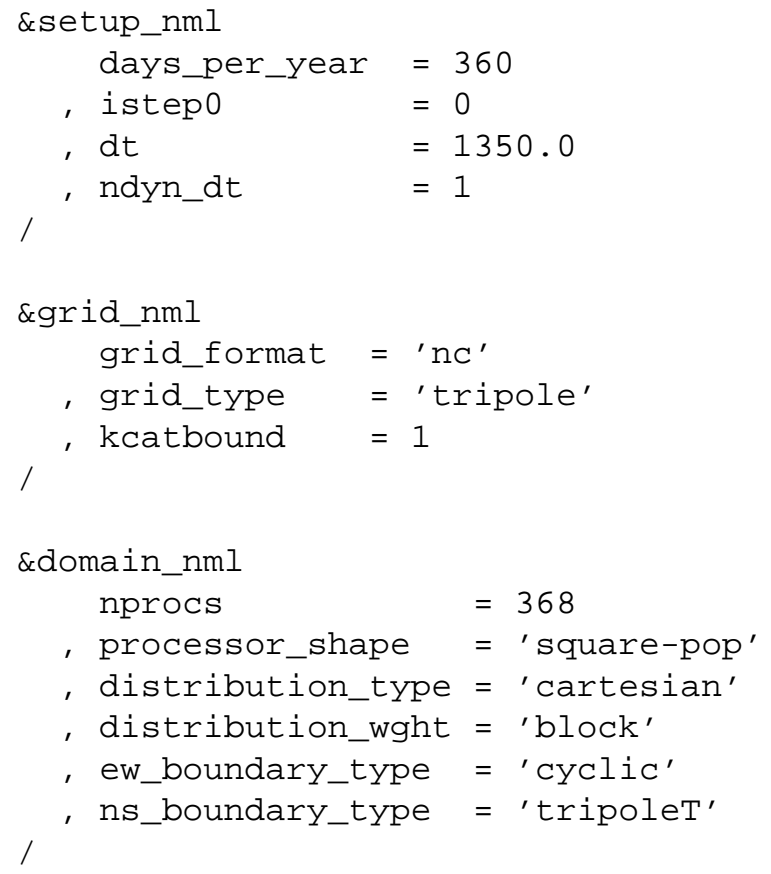

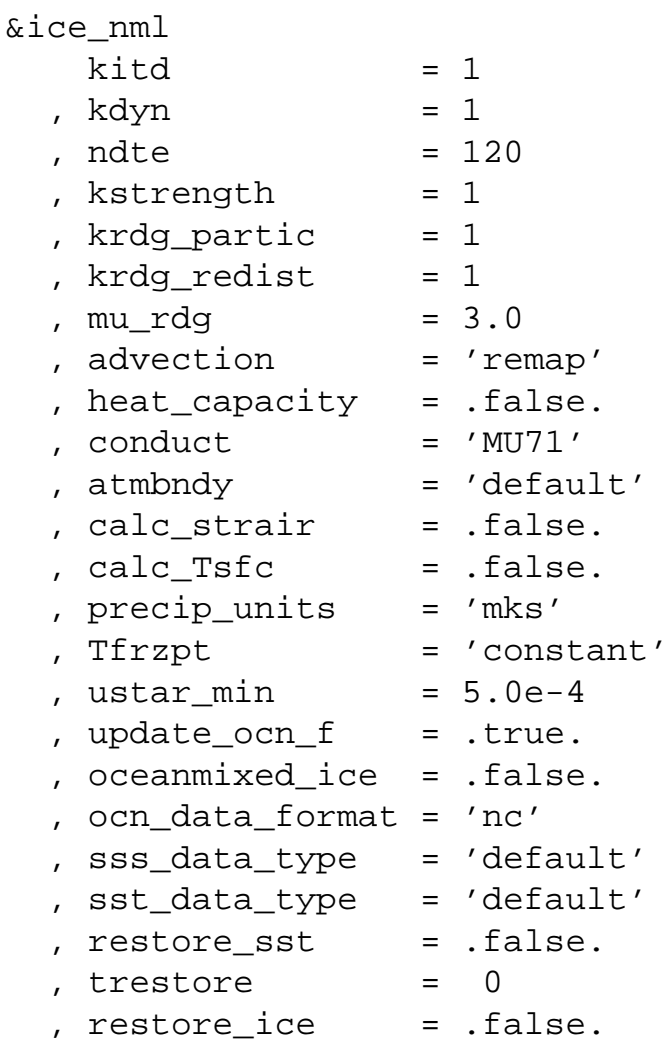




\section{Code availability}

The MetUM is available for use under licence. A number of research organisations and national meteorological services use the MetUM in collaboration with the Met Office to undertake basic atmospheric process research, produce forecasts, develop the MetUM code and build and evaluate Earth system models. For further information on how to apply for a licence see http://www.metoffice.gov.uk/research/ collaboration/um-collaboration.

JULES is available under licence free of charge. For further information on how to gain permission to use JULES for research purposes see https://jules.jchmr.org/ software-and-documentation.

The model code for NEMO v3.4 is available from the NEMO website (www.nemo-ocean.eu). On registering, individuals can access the code using the open-source subversion software (http://subversion.apache.org/).

The model code for CICE is freely available from the United States Los Alamos National Laboratory (http:// oceans11.lanl.gov/trac/CICE/wiki/SourceCode), again using subversion.

The versions and revisions of each model used in this paper are given in Table 1. A number of branches are applied to these codes. Please contact the authors for more information on these branches and how to obtain them.

Acknowledgements. We are grateful to Alison McLaren and Ed Blockley for useful comments on earlier drafts of the manuscript. This work was supported by the Joint DECC/Defra Met Office Hadley Centre Climate Programme (GA01101). We are grateful to the reviewers for their useful comments, which led to substantial improvements in this manuscript.

Edited by: A. Le Brocq

\section{References}

Best, M. J., Pryor, M., Clark, D. B., Rooney, G. G., Essery, R .L. H., Ménard, C. B., Edwards, J. M., Hendry, M. A., Porson, A., Gedney, N., Mercado, L. M., Sitch, S., Blyth, E., Boucher, O., Cox, P. M., Grimmond, C. S. B., and Harding, R. J.: The Joint UK Land Environment Simulator (JULES), model description Part 1: Energy and water fluxes, Geosci. Model Dev., 4, 677-699, doi:10.5194/gmd-4-677-2011, 2011.

Bitz, C. M. and Lipscomb, W. H.: An energy-conserving thermodynamic model of sea ice, J. Geophys. Res., 104, 15669-15677, 1999.

Bitz, C. M., Holland, M., Weaver, A., and Eby, M.: Simulating the ice-thickness distribution in a coupled climate model, J. Geophys. Res., 106, 2441-2463, 2001.

Blockley, E. W., Martin, M. J., McLaren, A. J., Ryan, A. G., Waters, J., Lea, D. J., Mirouze, I., Peterson, K. A., Sellar, A., and Storkey, D.: Recent development of the Met Office operational ocean forecasting system: an overview and assessment of the new Global FOAM forecasts, Geosci. Model Dev., 7, 2613-2638, doi:10.5194/gmd-7-2613-2014, 2014.

Cullen, M. J. P. and Davies, T.: A conservative split-explicit integration scheme with fourth-order horizontal advection, Q. J. Roy. Meteorol. Soc., 117, 993-1002, 1991.

Davies, T., Cullen, M. J. P., Malcolm, A. J., Mawson, M. H., Staniforth, A., White, A. A., and Wood, N.: A new dynamical core for the Met Office's global and regional modelling of the atmosphere, Q. J. Roy. Meteor. Soc., 131, 1759-1782, 2005.

Essery, R., Martin, E., Douville, H., Fernández, A., and Brun, E.: A comparison of four snow models using observations from an alpine site, Clim. Dynam., 15, 583-593, 1999.

Flato, G. and Hibler, W.: Ridging and strength in modeling the thickness distribution of Arctic sea ice, J. Geophys. Res., 100, 18611-18626, 1995.

HadGEM2 Development Team, The: Martin, G. M., Bellouin, N., Collins, W. J., Culverwell, I. D., Halloran, P. R., Hardiman, S. C., Hinton, T. J., Jones, C. D., McDonald, R. E., McLaren, A. J., O'Connor, F. M., Roberts, M. J., Rodriguez, J. M., Woodward, S., Best, M. J., Brooks, M. E., Brown, A. R., Butchart, N., Dearden, C., Derbyshire, S. H., Dharssi, I., Doutriaux-Boucher, M., Edwards, J. M., Falloon, P. D., Gedney, N., Gray, L. J., Hewitt, H. T., Hobson, M., Huddleston, M. R., Hughes, J., Ineson, S., Ingram, W. J., James, P. M., Johns, T. C., Johnson, C. E., Jones, A., Jones, C. P., Joshi, M. M., Keen, A. B., Liddicoat, S., Lock, A. P., Maidens, A. V., Manners, J. C., Milton, S. F., Rae, J. G. L., Ridley, J. K., Sellar, A., Senior, C. A., Totterdell, I. J., Verhoef, A., Vidale, P. L., and Wiltshire, A.: The HadGEM2 family of Met Office Unified Model climate configurations, Geosci. Model Dev., 4, 723-757, doi:10.5194/gmd-4-723-2011, 2011.

Hewitt, H. T., Copsey, D., Culverwell, I. D., Harris, C. M., Hill, R. S. R., Keen, A. B., McLaren, A. J., and Hunke, E. C.: Design and implementation of the infrastructure of HadGEM3: the nextgeneration Met Office climate modelling system, Geosci. Model Dev., 4, 223-253, doi:10.5194/gmd-4-223-2011, 2011.

Hibler, W.: A dynamical thermodynamic sea ice model, J. Phys. Oceanogr., 9, 817-846, 1979.

Hibler, W.: Modeling a variable thickness sea ice cover, Mon. Weather Rev., 108, 1943-1973, 1980.

Hunke, E. C.: Thickness sensitivities in the CICE sea ice model, Ocean Model., 34, 137-149, doi:10.1016/j.ocemod.2010.05.004, 2010.

Hunke, E. C. and Dukowicz, J. K.: The Elastic-Viscous-Plastic Sea Ice Dynamics Model in General Orthogonal Curvilinear Coordinates on a Sphere-Incorporation of Metric Terms, Mon. Weather Rev., 130, 1848-1865, 2002.

Hunke, E. C. and Lipscomb, W. H.: CICE: the Los Alamos sea ice model documentation and software users' manual, Version 4.1, LA-CC-06-012, Los Alamos National Laboratory, N.M., 2010.

Keen, A. B., Hewitt, H. T., and Ridley, J. K.: A case study of a modelled episode of low Arctic sea ice, Clim. Dynam., 41, 1229 1244, doi:10.1007/s00382-013-1679-y, 2013.

Laxon, S. W., Giles, K. A., Ridout, A. L., Wingham, D. J., Willatt, R., Cullen, R., Kwok, R., Schweiger, A., Zhang, J. L., Haas, C. Hendricks, S., Krishfield, R., Kurtz, N., Farrell, S., and Davidson, M.: CryoSat-2 estimates of Arctic sea ice thickness and volume, Geophys. Res. Lett., 40, 732-737, doi:10.1002/grl.50193, 2013.

Lipscomb, W.: Remapping the thickness distribution in sea ice models, J. Geophys. Res., 106, 13989-14000, 2001. 
Lipscomb, W. H. and Hunke, E. H.: Modeling sea ice transport using incremental remapping, Mon. Weather Rev., 132, 13411354, 2004.

Lipscomb, W. H., Hunke, E. C., Maslowski, W., and Jakacki, J.: Ridging, strength, and stability in high-resolution sea ice models, J. Geophys. Res., 112, C03S91, doi:10.1029/2005JC003355, 2007.

MacLachlan, C., Arribas, A., Peterson, K. A., Maidens, A., Fereday, D., Scaife, A. A., Gordon, M., Vellinga, M., Williams, A., Comer, R. E., Camp, J., Xavier, P., and Madec, G.: Global Seasonal Forecast System version 5 (GloSea5): a high resolution seasonal forecast system, Q. J. Roy. Meteor. Soc., 141, 10721084, doi:10.1002/qj.2396, 2014.

Madec, G.: NEMO Ocean Engine, Note du Pole de Modélisation, Institut Pierre-Simon Laplace (IPSL), France, No 27, ISSN No 1288-1619, 2008.

McLaren, A. J., Banks, H. T., Durman, C. F., Gregory, J. M., Johns, T. C., Keen, A. B., Ridley, J. K., Roberts, M. J., Lipscomb, W. H., Connolley, W. M., and Laxon, S. W.: Evaluation of the sea ice simulation in a new coupled atmosphere-ocean climate model (HadGEM1), J. Geophys. Res., 111, C12014, doi:10.1029/2005JC003033, 2006.

McPhee, M. G.: Turbulent heat flux in the upper ocean under sea ice, J. Geophys. Res., 97, 5365-5379, 1992.

Megann, A., Storkey, D., Aksenov, Y., Alderson, S., Calvert, D., Graham, T., Hyder, P., Siddorn, J., and Sinha, B.: GO5.0: the joint NERC-Met Office NEMO global ocean model for use in coupled and forced applications, Geosci. Model Dev., 7, 10691092, doi:10.5194/gmd-7-1069-2014, 2014.

Rae, J. G. L., Hewitt, H. T., Keen, A. B., Ridley, J. K., Edwards, J. M., and Harris, C. M.: A sensitivity study of the sea ice simulation in HadGEM3, Ocean Model., 74, 60-76, doi:10.1016/j.ocemod.20, 2014.

Rayner, N. A., Parker, D. E., Horton, E. B., Folland, C. K., Alexander, L. V., Rowell, D. P., Kent, E. C., and Kaplan, A.: Global analyses of sea surface temperature, sea ice, and night marine air temperature since the late nineteenth century, J. Geophys. Res., 108, 4407, doi:10.1029/2002JD002670, 2003.
Rothrock, D.: The energetics of the plastic deformation of pack ice by ridging, J. Geophys. Res., 80, 4514-4519, 1975.

Schweiger, A., Lindsay, R., Zhang, J., Steele, M., Stern, H., and Kwok, R.: Uncertainty in modeled Arctic sea ice volume, J. Geophys. Res., 116, C00D06, doi:10.1029/2011JC007084, 2011.

Semtner, A. J.: A model for the thermodynamic growth of sea ice in numerical investigations of climate, J. Phys. Oceanogr., 6, 379389, 1976.

Semtner, A. J.: A numerical study of sea ice and ocean circulation in the Arctic, J. Phys. Oceanogr., 17, 1077-1099, 1987.

Thorndike, A., Rothrock,, D., Maykut, G., and Colony, R.: The thickness distribution of sea ice, J. Geophys. Res., 80, 45014513, 1975.

Valcke, S.: OASIS3 User Guide (prism_2-5). PRISM Support Initiative No 3, 68 pp., 2006.

Walters, D. N., Brooks, M. E., Boutle, I. A., Melvin, T. R. O., Stratton, R. A., Wells, H., Williams, K. D., Bushell, A. C., Copsey, D., Earnshaw, P. E., Gross, M. S., Hardiman, S. C., Harris, C. M., Heming, J. T., Klingaman, N. P., Levine, R. C., Manners, J., Martin, G. M., Milton, S. F., Mittermaier, M. P., Morcrette, C. J., Riddick, T. C., Roberts, M. J., Sanchez, C., Selwood, P. M., Smith, C., Tennant, W. J., Vosper, S. B., Vidale, P. L., Wilkinson, J. M., Wood, N., Woolnough, S. J., and Xavier, P. K.: The Met Office Unified Model Global Atmosphere 6.0/6.1 and JULES Global Land 6.0/6.1 configurations, Geosci. Model Dev. Discuss., in preparation, 2015.

Williams, K. D., Harris, C. M., Bodas-Salcedo, A., Camp, J., Comer, R. E., Copsey, D., Fereday, D., Graham, T., Hill, R., Hinton, T., Hyder, P., Ineson, S., Masato, G., Milton, S. F., Roberts, M. J., Rowell, D. P., Sanchez, C., Shelly, A., Sinha, B., Walters, D. N., West, A., Woollings, T., and Xavier, P. K.: The Met Office Global Coupled model 2.0 (GC2) configuration, Geosci. Model Dev., 8, 1509-1524, doi:10.5194/gmd-8-1509-2015, 2015. 